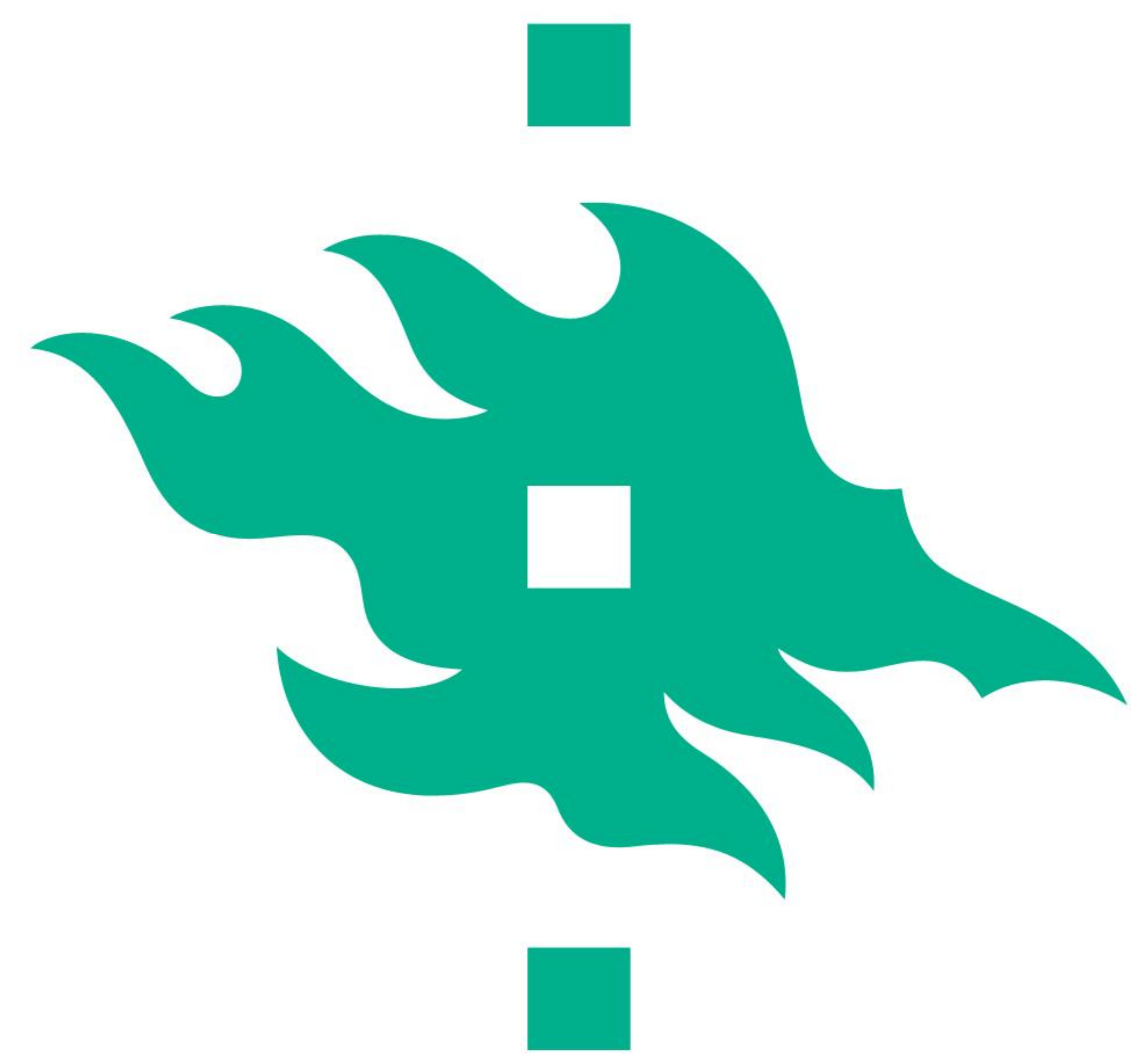

\title{
MAPPING THE RISK OF FOREST WIND DAMAGE USING AIRBORNE LASER SCANNING
}

\author{
Mikko Vastaranta \\ Ninni Saarinen \\ Markus Holopainen \\ Eija Honkavaara ${ }^{2}$ \\ Kimmo Nurminen ${ }^{2}$ \\ Paula Litkey ${ }^{2}$ \\ J uha Hyyppä2
}

${ }^{1}$ University of Helsinki, Department of Forest Sciences, first.last@helsinki.fi Finnish Geodetic Institute, Department of Remote Sensing and Photogrammetry

\section{BACKGROUND AND OBJ ECTIVE}

- National Land Survey of Finland (NLS) started collecting ALS-data in 2008 to provide new national elevation model

- The data is available at free of charge

- This data set has great potential and wide variety of possible applications in spatial modeling

- The objective of this study was to test the feasibility of ALS-data from NLS in mapping the risk of forest wind damage

\section{MATERIAL AND METHODS}

- The study area covered approximately $178 \mathrm{~km}^{2}$ of mainly managed boreal forests and agricultural fields

- The damages occurred during the winter storms on $26^{\text {th }}$ and $27^{\text {th }}$ of December 2011

- The used ALS data were acquired in 2008

- High resolution aerial imagery acquired after the damage were used for providing the ground truth data

- Systematic grid (16 m x $16 \mathrm{~m}$ ) was established and 400 sample grid cells were selected systematically and classified as damaged or undamaged

- Spatial factors explaining the damage probability were investigated using multivariate logistic regression model

- The predictors for risk model were extracted from the ALSderived surface models:

- Canopy Height Model

- Digital Terrain Model

\section{RESULTS AND DISCUSSION}

- The strongest predictors in the risk model were mean height of vegetation, canopy cover and elevation.

- Risk model based on ALS data provided a good agreement on detected damage areas.
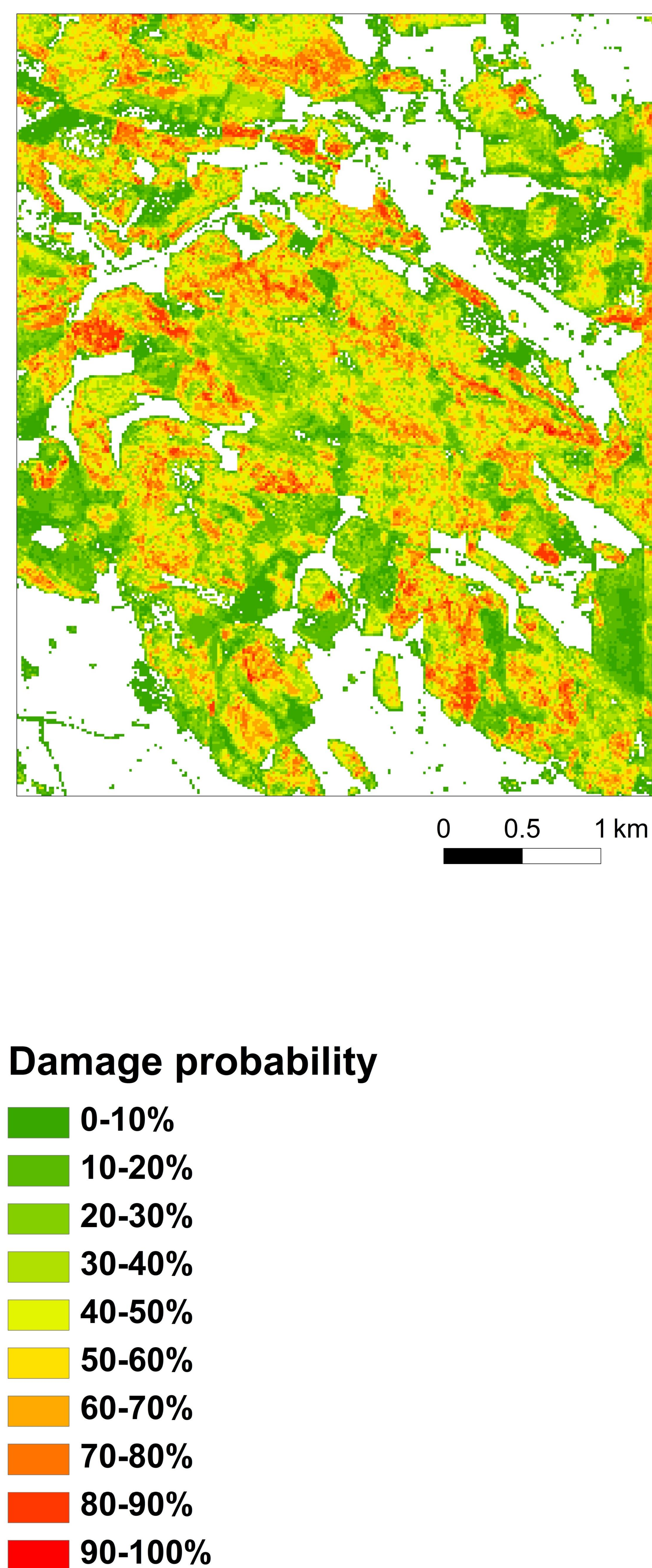

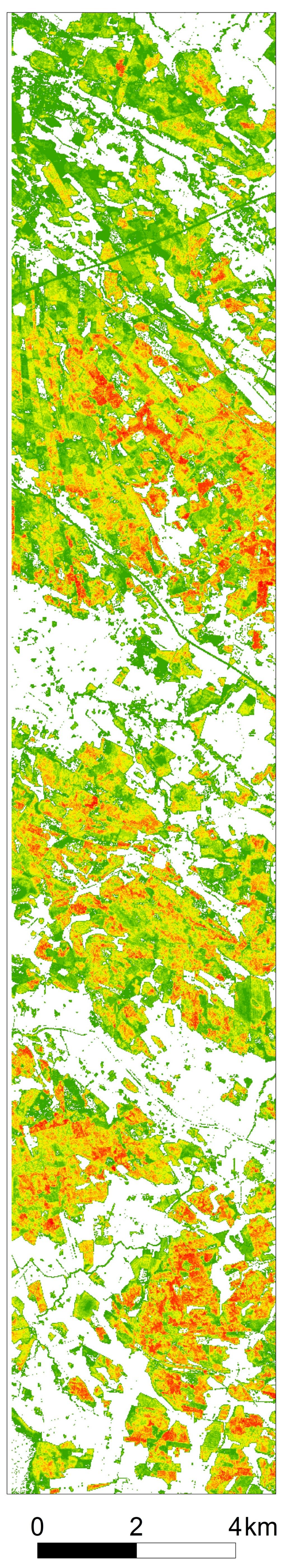

